\title{
Robert Torrens e a teoria clássica do lucro
}

\section{Palavras-chave}

economia clássica, valor trabalho, taxa de lucro, livre comércio

\section{Classificação JEL}

B10, B12, B16

\section{Keywords}

classical economics, labor theory of value, profit rate, free trade

\section{JEL Classification}

B10, B12, B16

\section{Resumo}

$\mathrm{O}$ artigo reconstitui a evolução da teoria dos lucros do coronel Robert Torrens com base em sua crítica à doutrina ricardiana do valor. Inicialmente, revisa-se a investida que promoveu contra a noção do tempo de trabalho como elemento exclusivo de regulação das trocas mercantis. Após, apresenta-se a defesa desse princípio por McCulloch e pelo próprio Ricardo. Prossegue-se com o exame das origens da abordagem sistêmica dos lucros de Torrens, baseada na interdependência recíproca dos setores produtivos. Contemplam-se, na sequência, as aplicações dessa teoria realizadas pelo coronel, notadamente na defesa do livre comércio. Ao final, destaca-se o caráter pioneiro de seu tratamento dos lucros no contexto da economia clássica.
Rogério Arthmar

\section{Abstract}

This paper reconstructs the evolution of Colonel Robert Torrens' theory of profits based on its critique of the Ricardian theory of value. Initially, it describes the attack conducted by him on the idea of the amount of labor being the sole factor to regulate mercantile exchanges. After that, McCulloch's and Ricardo's arguments in defense of this principle are presented. It continues by examining the origins of Torren's systemic approach to profits, based on the reciprocal interdependence of the productive sectors. Next, the applications of such theory carried out by the Colonel are considered, especially the support for free trade. Finally, it highlights the pioneer character of his approach to profits within the overall setting of classical economics. 


\section{1_Introdução}

Em seu segundo mandato entre os Comuns, no ano de 1833, o coronel da Marinha Real Robert Torrens ${ }^{1}$ prestou emotivo tributo à memória de David Ricardo. No pronunciamento, destacou ser o célebre economista merecedor de profundo respeito, tendo conquistado grande ascendência no campo da filosofia política e projeção inigualável no Parlamento, além de deixar saudade eterna entre os amigos (Hansard, 26 de março de 1833, p. 1101). Ricardo, de sua parte, chegou a imaginar Torrens adepto de suas ideias e voz importante na promoção das políticas corretas (carta a Hutches Trower, 13 de março de 1820, Works VIII, 2004, p. 163). Apesar do sincero sentimento do coronel e do acerto da intuição de Ricardo no que tange à defesa do livre comércio, o militar, em verdade, jamais esteve próximo de acolher a teoria ricardiana do valor. No prefácio da terceira edição do seu Essay on the external corn trade (doravante ECT ou Essay on corn trade, 1826), o leitor é advertido que a obra buscara inspiração nos escritos de Ricardo, mas que o autor jamais concordara com a pretensa oposição entre salários e lucros. Isso por entender tal conclusão apoiada em generalizações prematuras, oriundas de uma concepção abstrata do valor que conferia universalidade a uma situação particular, atribuindo a determinada causa única efeitos devidos à operação combinada de muitas (ECT, 1826, p. x-xiii). ${ }^{2}$

Qualificado por Schumpeter (1963, p. 490) um pensador de menor estatura, Torrens, mais recentemente, veio a ser considerado por O’Brien (2004, p. 5) um dos melhores teóricos do período clássico. Já Robbins (1958, p. 51), em seu extenso estudo sobre a obra do coronel, declarou que ele nada ofereceu de original à doutrina ricardiana dos lucros. Perante tais opiniões díspares, o presente artigo investiga em que medida elas podem ser julgadas pertinentes no que respeita à contribuição desse controverso pensador aos problemas centrais do valor e da taxa de lucro no âmbito da economia clássica. O plano expositivo aqui desenvolvido, porém, leva em conta 0 aporte pessoal de Torrens ao assunto, aspecto invariavelmente omitido na literatura. ${ }^{3}$ Para esse fim, reconstitui-se inicialmente a sua investida contra a noção do valor trabalho. Seguem os argumentos contrários elaborados por John R. McCulloch e Ricardo. Após, apresenta-se a visão sistêmica da economia e dos lucros concebida por Torrens, acompanhada pelas diversas aplicações teóricas de sua abordagem. Conclui-se pelo reconhecimento do tratamento inovador da questão do valor por parte do coronel ao admitir ele a necessidade de determinação simultânea dos preços e da taxa de lucro nas diferentes linhas de produção.

\section{2_Torrens contra 0 valor trabalho}

No dia 24 de fevereiro de 1815, conjuntamente com o Essay on profits de Ricardo, é publicada a primeira edição do Essay on corn trade, assinada por Torrens. O livro baseava-se nos "perspicazes" princípios de Adam Smith que, conforme o autor, já havia demonstrado os efeitos benéficos da livre ação dos negociantes de trigo em deslocar o grão no espaço, dos locais de fartura para os de carestia, bem como no tempo, aprovisionando estoques para os anos de escassez. Pelas mesmas razões, o comércio do cereal deveria ser praticado sem a interposição de barreiras nacionais, uma vez que dessa forma o preço mundial dos alimentos permaneceria estável e a fome seria erradicada da face das nações, constituindo-se a Holanda no mais bem-sucedido representante dessa sábia política (ECT, 1815, p. 1-35). Daí, então, que qualquer estímulo artificial à agricultura resultasse prejudicial ao país.

A sequência analítica de formação da renda idealizada por Torrens segue padrão inteiramente smithiano. À medida que a economia progride, a competição entre os capitalistas reduz a taxa de lucros na indústria e no comércio até 
o nível possível de ser obtido nas terras de menor fertilidade. Ao mesmo tempo, a demanda por mão de obra avança, elevando os salários e estimulando o crescimento da população que, por sua vez, expande a procura por alimentos, fornecendo o motivo para a ocupação das terras de desempenho inferior. "Com o tempo, o cultivo ascende às colinas e escala as montanhas, até o país assumir o aspecto de um jardim universal" (ECT, 1815, p. 51). ${ }^{4}$

Esse cenário idílico, todavia, seria desfeito pelo protecionismo à agricultura, ocasionando perdas à indústria, ao comércio e à população. A majoração do preço do trigo, sancionada pelas leis tarifárias em vigor, teria sido apropriada pelos donos das terras quando da renovação dos contratos de aluguel nos lotes de rendimento superior, além de elevar o custo natural do trabalho que, repassado aos preços em geral, ocasionaria um movimento inflacionário. "Cada aumento no preço monetário do trigo, portanto, eleva o preço do trabalho e, por essa via, o preço de todas as necessidades da vida" (ECT, 1815, p. 83-84). O desfecho do processo não fica claro no texto, dado que os salários necessitariam de novo reajuste posterior, de sorte que o término da espiral trigo-salários passaria a depender de considerações de ordem monetária, como o próprio Torrens admite, mas não chega a esclarecer de forma satisfatória. ${ }^{5}$

De resto, cabe assinalar aqui passagem significativa para o enfoque futuro do valor por parte do coronel, na qual é contestado o Relatório dos Comuns que previa, como resultado do protecionismo, a expansão do cultivo de trigo no país e a queda gradual no seu custo de produção. Torrens objeta que se o preço interno do cereal caísse abaixo da barreira tarifária (80 shillings por quarter), as terras de menor rendimento seriam abandonadas por não proporcionarem lucro suficiente ao fazendeiro: "Se existe em todo o espectro da ciência princípio universalmente aceito e completamente indiscutível", adverte ele, "é que nenhum artigo pode ser trazido permanentemente ao mercado a não ser a preço suficiente para repor, com lucro adequado, as despesas de produção" (ECT, 1815, p. 212).

Torrens viria a intervir diretamente na controvérsia sobre o valor com a publicação, na revista Edinburgh Magazine, do artigo Strictures on Mr. Ricardo's doctrine respecting exchangeable value (1818, assinado R., doravante Strictures). De início, ele se declara partidário da concepção de Smith, que confinara a um estágio primitivo da sociedade a validade das trocas segundo o trabalho incorporado nos produtos. Ricardo, de acordo com o coronel, teria se equivocado ao insistir que, no mundo capitalista, $o$ trabalho continuaria a ser a fonte exclusiva do valor. ${ }^{6}$ Se numa economia de mercado o preço de venda deve necessariamente superar os desembolsos com salários, enquanto as taxas de lucro tendem ao nivelamento pela ação da concorrência dos capitais em suas diversas aplicações, então o valor das mercadorias deveria ser proporcional aos capitais nelas investidos, em vez de estar regulado pelo trabalho despendido em sua produção.

Como lhe era característico, Torrens desenvolve vários exemplos numéricos em apoio ao seu raciocínio. Vejamos um deles, no qual dois artigos contendo a mesma quantidade de trabalho, tanto na forma direta quanto nas matérias-primas utilizadas, fornecem valores distintos perante taxa de lucro de $20 \%$ e salário de um shilling por jornada de trabalho. O produtor A compra certa quantidade de seda produzida por 90 dias de trabalho ao preço de 108 s, no qual consta o lucro corrente sobre o gasto de 90s, e contrata 10 trabalhadores para processar a seda. $O$ produtor $B$, por seu turno, adquire lã bruta produzida por 10 dias de trabalho ao preço de 12s, lucro incluído, e contrata 90 homens para tecer o material. Ao final, o preço da seda processada atingiria $142 s=(1,2)(108 s+10 s)$, e o do tecido de lã $122 s=(1,2)(12 s+90 s)$, valores distintos para o mesmo tempo de trabalho contido em cada mercadoria, isto é, 100 dias. Os demais exemplos 
contemplam diferenças de salário, de durabilidade dos capitais e na composição entre capital fixo e circulante, todos fornecendo valores díspares daqueles obtidos pela adição simples do trabalho direto e indireto invertido em cada um dos bens.

O ponto central da exposição crítica conduzida por Torrens consiste na circunstância de os produtos serem trocados na proporção do trabalho neles incorporado, ideia de Ricardo, unicamente no caso específico em que capitais de mesma magnitude proporcionassem emprego a quantidades iguais de trabalho. Mas isso, assinala o coronel, teria lugar apenas por "coincidência fortuita". Em geral, capitais iguais mobilizariam quantidades diferentes de trabalho, embora viessem a possuir valores equivalentes. Se, por outro lado, quantidades idênticas de trabalho resultassem de capitais distintos, então os valores, não obstante, seriam diferentes. Smith, portanto, teria agido de forma acertada ao repelir o trabalho como fonte do valor na produção capitalista, enquanto Ricardo estaria errado ao insistir na validade de tal norma. Nos termos de Torrens:

\begin{abstract}
Mas como capitais equivalentes dificilmente possuem graus de durabilidade precisamente iguais, isso, em vez de limitar o que ele [Ricardo] chama de princípio geral, subverte-o totalmente, e prova que o valor relativo de todas as coisas está determinado não pelas quantidades de trabalho requeridas para produzi-las, mas pela operação universal da lei da concorrência, que iguala as taxas de lucro e, consequentemente, faz os resultados obtidos pelo emprego de capitais equivalentes iguais em seus valores de troca (Torrens, 1993 [1818], p. 80).
\end{abstract}

Tudo isso se assemelha mais a uma diferença de ênfase do que de conteúdo, já que as violações ao princípio do valor trabalho idealizadas por Torrens seguem, em linhas gerais, os casos contemplados pelo próprio Ricardo nos Principles (Works I, 2004, p. 56-66). ${ }^{7}$ Um aspecto da análise desenvolvida no artigo, contudo, assumiria papel relevante em momento posterior, qual seja, o fato de, no exemplo reproduzido acima, ser aplicado o critério da taxa uniforme de lucro sobre os capitais no cálculo dos valores tanto dos insumos quando dos produtos. Esse procedimento representava novidade analítica importante e será considerado à frente, quando as ideias mais elaboradas de Torrens sobre a questão vierem a ser detalhadas. Por ora, passemos à resposta de McCulloch, publicada na edição de novembro da Edinburgh Magazine, bem como à manifestação de Ricardo sobre as críticas indicadas. ${ }^{8}$

\section{3_A defesa da teoria ricardiana}

$\mathrm{O}$ artigo de McCulloch, Mr. Ricardo's theory of exchangeable value vindicated from the objections of $R$, inicia reafirmando a tese de Ricardo de que as mercadorias deveriam ser intercambiadas com base não apenas no trabalho direto nelas contido, mas também no indireto, isto é, naquele materializado nos instrumentos de produção. Em seguida, consta o seguinte registro inusitado: "Até onde sei, o Senhor Ricardo não afirmou em lugar algum que quando capitais iguais possuem diferentes graus de durabilidade, os produtos de quantidades iguais de trabalho não terão valores iguais" (McCulloch, 1818, p. 430). Ricardo assim o fizera efetivamente (ver nota 6), mas o seu paladino não parece ciente disso e prossegue inabalado.

Diante de tal situação, continua o escocês, o trabalho acumulado nos diversos instrumentos seria repassado gradualmente aos produtos, de modo que a troca pela regra do tempo de trabalho estaria inteiramente preservada. McCulloch declara estranhar que Torrens considerasse essa hipótese 
capaz de subverter a teoria de Ricardo, pois se as trocas se processassem de outra maneira, aí sim ocorreria violação do preceito ricardiano. Sustenta ainda ser incorreto o ajuste dos custos pela taxa de lucro, como fizera Torrens no caso da seda e da lã, pois o tempo envolvido no processamento das matérias-primas teria sido de somente um dia. Por fim, conclui encontrar pouco do que discordar das críticas apresentadas, dado que elas poderiam ser reduzidas às diferenças na vida útil dos capitais, quadro inteiramente condizente com a teoria do valor sugerida por Ricardo. Em suma, contrariamente ao proclamado pelo coronel, os contraexemplos concebidos em Strictures nada mais seriam do que casos particulares da abordagem geral desenvolvida nos Principles.

Ele admite que o valor de troca das mercadorias deva ser regulado pela quantidade de capital que se necessita gastar em sua produção. Isso nada mais é do que o reconhecimento da veracidade da teoria do Senhor Ricardo. $O$ que é capital, senão trabalho acumulado? E nos contar que o valor das mercadorias depende da quantidade de capital consumida ao produzi-las é apenas outra maneira, mas extremamente incômoda, sinuosa e incorreta, de nos informar que o valor depende da quantidade total de trabalho requerido para trazê-las ao mercado (McCulloch, 1818, p. 4331, destaques no original).

Sabe-se que Ricardo discutira o assunto com Torrens anteriormente naquele ano, tendo sobrevivido dois fragmentos escritos do episódio. No material assinado pelo segundo, descreve-se o emprego de capitais equivalentes, um na produção de linho e outro na de cambraia, investidos em dois estágios. No primeiro deles, os capitais na forma de bens de subsistência financiariam o cultivo das plantas e de novos alimentos, a serem utilizados pelos trabalhadores na segunda etapa do processo, a de fabricação do produto final. Os valores respectivos, conforme Torrens, resultariam iguais por terem se originado de capitais de mesma magnitude, mas como as combinações entre mão de obra e matérias-primas seriam supostamente diferentes nas duas linhas de produção, tais valores não refletiriam o conteúdo de trabalho em cada mercadoria (Works IV, 2004, p. 309, n. 1, p. 314-315).

Ricardo, em suas anotações, acusa o coronel de haver realizado dupla contabilidade do trabalho despendido nos bens de subsistência durante ambas as etapas da produção. Ainda, considera o exemplo mal formulado, apontando residir a dificuldade concreta da questão no tempo decorrido entre a colheita da matéria-prima e o seu processamento efetivo. Entende Ricardo ser o problema similar ao exposto nos Principles para os capitais de composição distinta, mas permanece em dúvida sobre o adequado enquadramento das matérias-primas, se na categoria de capital fixo ou na de circulante (Works IV, 2004, p. 309-313).

Verifica-se, nessa fase inicial de divulgação da teoria ricardiana do valor, que tanto os críticos quanto os defensores falharam não só em compreender devidamente, mas também em explorar os novos conceitos. ${ }^{9}$ Para Ricardo, que discriminara uma série de ressalvas em sua exposição original do assunto, a tendência natural era julgar os casos anômalos divisados por Torrens como simples variantes das exceções listadas nos Principles. Tanto que, no seu caderno de notas, ele transcreve diversos trechos do livro nos quais julga haver contemplado as objeções arroladas no artigo da Edinburgh Magazine (Works IV, 2004, p. 315-318). Ricardo, ademais, demonstra insatisfação, assim como James Mill, com a réplica de McCulloch, e redige nova resposta a Torrens que, lamentavelmente, se extraviou. Em carta a James Mill à época, porém, ele explica com certa minúcia o seu ponto de vista 
sobre o objeto de discussão. As críticas dirigidas à sua teoria concentravam-se em aspectos ligados ao valor absoluto das mercadorias, quando a sua preocupação central residia nos fatores determinantes dos valores relativos. Além disso, contrariamente ao que pensava Torrens, ele não divergia de Smith por este último haver negado a influência do trabalho na determinação do valor em condições capitalistas, mas sim por ter ele afirmado que, com a apropriação privada do capital, a taxa de lucro representaria acréscimo ao valor das mercadorias (28 de dezembro de 1818, Works VII, 2004, p. 377).

Na segunda edição dos Principles (1819), o capítulo sobre o valor sofre modificações superficiais, sendo dividido em cinco seções, mas com grande parte do conteúdo original intacto. Como concessão a Torrens, todavia, Ricardo passa a considerar as matérias-primas como parte do capital circulante, reconhecendo que elas poderiam, eventualmente, ser incluídas no capital fixo, dependendo de seu tempo de rotação em cada processo produtivo particular. Tais diferenças afetariam também o valor de troca das mercadorias perante variação nos salários, admite Ricardo, mas nos moldes dos efeitos analisados na primeira edição do livro. Ou seja, a crítica de Torrens teve repercussão mínima nas posições de Ricardo sobre os determinantes das trocas em condições capitalistas, como ele mesmo relatou a McCulloch ao final de 1819: "Estou mais convencido do que nunca que o grande regulador do valor é a quantidade de trabalho requerida para produzir a mercadoria avaliada. Há muitas modificações que devem ser admitidas na doutrina [...] mas isso não invalida a doutrina em si” (18 de dezembro de 1819, Works VIII, 2004, p. 142).

\section{4_A visão sistêmica da economia por Torrens}

Em outubro de 1819, Torrens inclui na Edinburgh Review o artigo Mr Owen's plan for relieving the national distress, no qual ataca duramente as propostas do filantropo Robert
Owen para aliviar o desemprego. Este último recomendava o estabelecimento de comunidades autônomas, com uns poucos milhares de pessoas, nas quais os residentes exerceriam uma diversidade de funções e habitariam prédios na forma de paralelogramos (Owen, 1817, p. 53-64). Torrens julga a ideia bem-intencionada, mas desprovida de fundamento na economia política, assemelhando-se, mais propriamente, a um vistoso meteoro cujo brilho fulgurante anteciparia o caos e o desastre. A origem efetiva do desemprego à época residiria, segundo ele, na falta de demanda por mão de obra decorrente do estado de estagnação da agricultura, das manufaturas e do comércio. Para reverter tal quadro, seria indispensável o correto entendimento dos fatores causais da taxa de lucro da economia. E, no tocante a esse tema, Torrens evidencia haver se movido decisivamente para o campo ricardiano, apoiando-se no Essay on profits e, em menor grau, nos Principles. ${ }^{10}$

No artigo sobre Owen, o primeiro fator apontado por Torrens a influenciar a rentabilidade geral dos negócios consistiria na qualidade do solo, estimada como o saldo material entre o trigo colhido e aquele adiantado na forma de sementes e de salários. O segundo determinante da taxa de lucro envolveria a produtividade do trabalho tanto na agricultura quanto nas manufaturas, pois as melhorias no trato da terra reverteriam em maior colheita, ao passo que os aperfeiçoamentos na operação dos bens processados reduziriam os custos da produção agrícola. Por fim, dadas as condições técnicas de produção prevalecentes na economia, aumentos salariais reverteriam em redução na taxa de lucro. A crise e o desemprego do período, em vista de tais esclarecimentos, resultariam do estreitamento do retorno dos capitais promovido pela ocupação de terras de menor fertilidade, pelas restrições comerciais impeditivas da importação de alimentos mais baratos, bem como pelo excesso de tributação a onerar os lucros (Torrens, 1993 [1819], p. 83-92). 
O texto em foco merece destaque por se constituir na primeira oportunidade em que Torrens, para ilustrar a sua análise, expressa a taxa de lucro em termos físicos. E, indo além de Ricardo, ele inova ao introduzir o cálculo da rentabilidade geral da economia abarcando os dois setores, agrícola e manufatureiro, com utilização recíproca de insumos. A intenção era refutar a tese ricardiana de oposição entre salários e lucros, cuja validade, para o coronel, estaria restrita ao caso de constância das condições técnicas da economia. Em presença de aperfeiçoamentos nos "poderes efetivos" de se produzir riqueza, a oposição deixaria de existir, visto que tanto os lucros quanto os salários seriam capazes de aumentar em termos reais. $O$ exemplo utilizado por Torrens, de tipo insumo-produto, embora singelo, vale a pena ser replicado aqui, pois, se por um lado reflete inegável avanço analítico, evidencia, de outro, importante dificuldade de seu pensamento na ocasião. Isso porque as proporções entre o produto final e o uso conjunto dos insumos nas duas atividades são idênticas, de modo a possibilitar a estimativa material da taxa de lucro sem a necessidade de interveniência dos preços de cada bem. A economia hipotética de Torrens produz trigo e trajes, cada setor utiliza 100 homens a um salário anual de 1 quarter de trigo e de 1 traje, sendo a taxa de lucro original $r=50 \%$ (situação A). Após melhoria técnica de caráter geral, a produtividade cresce, os salários passam a 1,5 quarter de trigo e 1,5 traje, enquanto a taxa de lucro alcança 66\% (situação B), conforme a Tabela 1.

Assumindo abordagem mais ampla do processo circular de reprodução econômica, Torrens se vê em condições de avaliar o comportamento da taxa de lucro de maneira distinta daquela adiantada por Ricardo. Uma vez aceita a interdependência entre os setores no tocante aos insumos utilizados, tornava-se possível até mesmo elevação da taxa de lucro a despeito do plantio em lotes de menor fertilidade. $\mathrm{O}$ aumento da população, de acordo com Torrens, não só forçaria a ocupação de terras de qualidade inferior, como também, segundo a tese smithiana, propiciaria maiores oportunidades de emprego aos capitais, estimulando melhorias técnicas na produção manufatureira com potencial de reduzir os custos dos bens processados em ritmo superior ao aumento nos custos dos alimentos e das matérias-primas. No longo prazo, porém, as dificuldades da produção agrícola acabariam por prevalecer, forçando a economia ao estado estacionário, embora até lá o trajeto pudesse apresentar grandes reversões: "No progresso da sociedade, portanto, as duas causas principais que determinam a taxa de retorno sobre o capital produtivo são como músculos antagonistas, modificando e balanceando a ação um do outro" (Torrens, 1993 [1819], p. 87).

\begin{tabular}{|c|c|c|c|}
\hline \multirow{2}{*}{$\begin{array}{l}\text { Situação B } \\
r=66 \%\end{array}$} & \multicolumn{2}{|l|}{ Insumos } & \multirow{2}{*}{ Produtos } \\
\hline & Trigo & Trajes & \\
\hline Trigo & 150 & 150 & 500 \\
\hline Trajes & 150 & 150 & 500 \\
\hline & 300 & 300 & \\
\hline
\end{tabular}

Fonte: Torrens (1819, p. 86). 
O salto qualitativo na teoria do valor de Torrens teria lugar com a segunda edição do Essay on the influence of the external corn trade (EICT, 1820, título ligeiramente alterado). No quadro da produção capitalista, afirma o coronel, o princípio da concorrência universal poderia ser representado por meio de uma estrutura básica formal, tendo como pressupostos: (a) a interdependência entre todos os setores, cada qual utilizando algum insumo dos demais; (b) existência obrigatória de um excedente físico na fabricação ou no cultivo de cada bem em relação à quantidade total utilizada como capital pelo conjunto das unidades produtivas; (c) igualdade entre a oferta e a demanda de cada produto final; (d) salários uniformes, e (e) taxa de lucro comum para toda a economia, nivelada pela concorrência e proporcional aos custos de produção.

A fim de examinar os desdobramentos teóricos de tais pressupostos, Torrens adiciona um quarto capítulo ao livro, contendo quase uma centena de páginas, onde utiliza repetidas vezes a sua nova metodologia de análise (EICT, 1820, p. 359-442). A rigor, são 24 ilustrações numéricas de economias simplificadas, mas formuladas com base na novidade fundamental de superposição dos preços e da taxa de lucro ao sistema quantitativo esboçado no artigo sobre Owen. Nos exemplos que idealiza, Torrens encontra-se claramente em processo de aprendizado da álgebra para a apuração dos preços relativos e da taxa de lucro, a qual nenhum economista contemporâneo parecia dominar. ${ }^{11}$ Ele próprio trata de ressaltar a natureza inovadora de sua teoria:

As leis que, em verdade, determinam a diferença entre o valor do produto em seu estado bruto e manufaturado não foram, até onde eu saiba, estabelecidas por qualquer autor precedente; devo, portanto, apelar à indulgência do leitor enquanto tento oferecer aquilo que, assim me parece, tem permanecido um

desiderato na ciência econômica (EICT, 1820, p. 360).

A forma específica do sistema de Torrens e que serve de base a todos os seus cálculos, embora não seja por ele apresentada explicitamente, encontra-se expressa a seguir, onde $x_{i j}$ indica a quantidade do insumo $i$ utilizada na produção do bem $j, X_{j}$ representa a produção total do bem $j$ (1=agricultura, $2=$ manufaturas), $p_{a}$ é o preço do produto agrícola, $p_{m}$ é o preço do artigo manufaturado e $r$ denota a taxa de lucro (esta representação formal não é, com efeito, apresentada explicitamente por Torrens; sobre as possíveis razões, veja-se Hisamatsu (2009)).

$$
\begin{aligned}
& \left(x_{11} p_{a}+x_{21} p_{m}\right)(1+r)=X_{1} p_{a} \\
& \left(x_{12} p_{a}+x_{22} p_{m}\right)(1+r)=X_{2} p_{m}
\end{aligned}
$$

O sistema (1)-(2) tem duas equações e três incógnitas, os dois preços e a taxa de lucro, bastando definir um dos preços como numerário para se encontrar as soluções. Isso é o que faz Torrens, embora seu método de resolução seja bastante peculiar, como será visto na próxima seção.

\section{5_Aplicações do sistema de Torrens}

A ferramenta analítica desenvolvida pelo coronel, representada no sistema (1)-(2), revela-se poderosa, sendo utilizada logo no segundo parágrafo do capítulo indicado quando ele refuta, sem demora, a proposta smithiana de constituir-se o trigo medida invariante do valor, contrapondo que nenhum bem possuiria custos imutáveis. "O valor de cada mercadoria, cuja quantidade pode ser aumentada pela indústria humana, é determinado pelo custo de produção", explica Torrens, ao que agrega,"e como o custo de produzir trigo pode aumentar 
ou diminuir sem ensejar variação proporcional no custo de produzir outras coisas, uma dada quantidade de trigo pode comprar mais ou menos de outros artigos" (EICT, 1820, p. 349350). A seguir, ele rebate a tese fisiocrata de produtividade exclusiva da agricultura, lembrando que qualquer capital aplicado nas manufaturas deveria receber remuneração igual àquela auferida na exploração do solo. "Pela perpétua operação da lei da concorrência, o emprego de capitais equivalentes por tempo igual fornece resultados de idêntico valor de troca" (EICT, 1820, p. 360-361).

Torrens recorre novamente ao sistema (1)-(2) na exposição dos determinantes da taxa de lucro e que, como visto, compreenderiam a produtividade agrícola na obtenção das necessidades da vida, o grau de destreza do trabalho no cultivo e nas manufaturas e, ainda, a taxa real de salários, ou seja, os bens consumidos pelo trabalhador durante o processo de produção (EICT, 1820, p. 384-385). Assume ele, então, determinada configuração produtiva de referência para a economia, com $x_{11}=x_{12}$ e $x_{21}=x_{22}$, de modo que os custos são forçosamente iguais nos dois setores, enquanto a produção final $X_{1}$ ou $X_{2}$ é superior e proporcional ao uso total dos insumos, estando a taxa de lucro, portanto, definida automaticamente na forma material.

Com isso, torna-se imediato a Torrens ilustrar os efeitos dos fatores listados sobre os preços relativos e a taxa de lucro. No caso de declínio na fertilidade do solo, é suficiente aplicar uma redução em $X_{1}$. Da mesma forma, o resultado de um acréscimo na produtividade do trabalho é avaliado por meio de um aumento em $X_{1}$ ou $X_{2}$. Por fim, o impacto de um reajuste nos salários é expresso mediante incremento proporcional nos insumos $x_{i j}$, mantendo-se constantes $X_{1}$ e $X_{2}$ (EICT, 1820, p. 390-394).

Outro uso interessante da nova ferramenta de Torrens ocorre no curso de sua refutação das teses do reverendo Robert T. Malthus favoráveis às Corn Laws e contrárias à teoria da renda fundiária de Ricardo, a qual apregoava os efeitos benéficos do barateamento do trigo sobre a taxa de lucro manufatureira. Malthus, entre outras coisas, propôs o enigma de que se o preço dos alimentos aumentasse em razão do progresso da acumulação e da restrição às importações dos cereais, então o produto agrícola alcançaria maior poder de compra ante os bens manufaturados, implicando queda nos custos reais do cultivo doméstico e consequente elevação da lucratividade do setor, em especial nas áreas de maior fertilidade (carta a Ricardo, 12 de março de 1815, Works VI, 2004, p. 185-186; Malthus, 1815, p. 24-27). ${ }^{12}$

Torrens rebate este argumento mostrando que se aumentos nos custos da produção agrícola elevam de fato o preço relativo do trigo, eles reduzem, ao mesmo tempo, a taxa geral de lucro.Admita-se, então, seguindo o seu exemplo, que em determinado período um fazendeiro empregue 50 homens, ao salário anual de um quarter de trigo e um traje, além de 50 quarters de trigo como sementes, obtendo daí 300 quarters de trigo, enquanto o produtor manufatureiro, com custos iguais, confecciona 150 trajes. ${ }^{13}$ Verifica-se, sem demora, a prevalência de uma razão de troca de 2 quarters de trigo por 1 traje, ou seja, $p_{m} / p_{a}=2$, de onde se chega à taxa de lucro $r=50 \%$, a qual, de resto, poderia ser estimada diretamente pela comparação entre o uso total de insumos e a produção final correspondente.

Se a produção manufatureira, contudo, permanece inalterada e a exploração agrícola avança sobre solo inferior em período subsequente, os mesmos custos em quarters de trigo e em trajes renderão colheita menor, por exemplo, 250 quarters de trigo. Nesse caso, importa assinalar, já não é mais possível apurar a taxa de lucro em termos estritamente materiais, uma vez que a proporcionalidade entre insumos e produtos deixa de existir. É indispensável o recurso aos preços dos bens. Mas como os custos permanecem nivelados nos dois setores, dada a forma específica do problema, os valores da 
Tabela 2_Sistema de Torrens e o enigma de Malthus

\begin{tabular}{|c|c|c|c|c|c|c|}
\hline \multirow[b]{2}{*}{ Setores } & \multicolumn{3}{|c|}{ Período 1} & \multicolumn{3}{|c|}{ Período 2} \\
\hline & $x_{1 j}$ & $x_{2 j}$ & $X_{i}$ & $x_{1 j}$ & $x_{2 j}$ & $X_{i}$ \\
\hline Agricultura & 100 & 50 & 300 & 100 & 50 & 250 \\
\hline \multirow[t]{2}{*}{ Manufaturas } & 100 & 50 & 150 & 100 & 50 & 150 \\
\hline & \multicolumn{2}{|c|}{$p_{m} / p_{a}=2,0$} & $r=50 \%$ & \multicolumn{2}{|c|}{$\mathrm{p}_{\mathrm{m}} / \mathrm{p}_{\mathrm{a}}=1,6^{\mathrm{a}}$} & $r=38 \%$ \\
\hline
\end{tabular}

Fonte: EICT (1820, p. 398-401). Obs.: (i) valores corretos (a) pm/pa=1,66 e (b) $\mathrm{r}=36,3 \%$; (ii) $\mathrm{x} 1 \mathrm{j}=$ quarters de trigo, $\mathrm{x} 2 \mathrm{j}=$ trajes.

oferta total de trigo e de trajes devem ser idênticos, ou seja, $250 p_{a}=150 p_{m}$, de onde $p_{m} / p_{a}=250 / 150=1,66$, denotando maior poder de compra do produto agrícola perante o manufaturado. A partir disso e assumindo-se um preço qualquer $p_{a}$ para o trigo, encontra-se o preço $p_{m}$ correspondente e a taxa de lucro $r=36,3 \%$, inferior, portanto, à taxa precedente $r=50 \% .{ }^{14}$ Logo, o enigma estaria solucionado e a tese de Malthus, embora correta no tocante aos preços relativos, decididamente refutada em sua previsão sobre o comportamento dos lucros.

Pela exposição anterior, percebe-se ser simples e engenhoso o método de resolução do sistema (1)-(2) elaborado pelo coronel. Ele não calcula os preços e a taxa de lucro em todos os exemplos que examina em seu livro, mas, quando o faz, assume custos proporcionais ou idênticos entre os setores, ou seja, $x_{11}=k x_{12}$ e $x_{21}=k x_{22}$, para um dado $k>0$ (na maioria das vezes, ele adota $k=1$ ). Pelo princípio de rentabilidade equivalente dos capitais, as receitas de vendas nos dois setores devem ser iguais ou proporcionais, o que implica $p_{a} X_{1}=k p_{m} X_{2}$. Os preços relativos, portanto, podem ser calculados imediatamente pelo quociente $p_{m} / p_{a}=(1 / k)\left(X_{1} / X_{2}\right) \mathrm{e}$, após a atribuição de algum valor arbitrário a $p_{a}$, é simples estimar $p_{m}$ (ou vice-versa) e a taxa de lucro correspondente r. Como Torrens enfatiza diversas vezes: "Pela ação permanente da lei da competição, o emprego de capitais iguais por períodos iguais fornece resultados equivalentes para os valores de troca" (EICT 1820, p. 361; para o caso de custos proporcionais, veja-se p. 365 ).

Embora alguns economistas modernos defendam haver Torrens concebido o seu esquema analítico com base no Essay on profits de Ricardo, utilizando uma taxa de lucro estritamente material e de natureza agrícola, tal leitura não se afigura convincente. ${ }^{15} \mathrm{O}$ motivo é que essa interpretação se apoia no caso particular $x_{21}=0$ e, portanto, $r=\left(X_{1} / x_{11}\right)-1$, de modo que a taxa de lucro independe dos preços relativos. Mas situação similar é admitida por Torrens em apenas três dos 24 exemplos de seu livro, quando ele combate a escola fisiocrata ao arguir que qualquer magnitude da taxa de lucro puramente agrícola seria a fortiori replicada nas manufaturas (ECT, 1820, p. 360-366). Mesmo no caso geral $x_{i j}>0$, a existência de uma taxa de lucro de caráter puramente material pressupõe produto excedente com proporção uniforme em relação ao uso total dos diversos insumos. Essa configuração específica do modelo, como visto, mostrou-se extremamente limitada para analisar os efeitos de variações nos determinantes da lucratividade da economia e, assim, possibilitar investida mais consistente contra o discurso protecionista visando à promoção do livre comércio, objetivo maior de Torrens (EICT, 1820, p. 366).

O último e talvez o mais efetivo uso do sistema (1)-(2) ocorre na análise quantitativa das trocas internacionais. Em países jovens e pouco populosos, como a América de então, afirma o coronel, somente as terras de melhor qualidade seriam cultivadas, enquanto a escassez de habitantes restringia o tamanho dos mercados e, por consequência, $o$ grau de divisão do trabalho passível de ser alcançado pelas manufaturas. Por outro lado, em nações antigas e populosas, como a Inglaterra, detentora de grandes mercados, a divi- 
Tabela 3_ Efeito do livre comércio, Torrens 1820

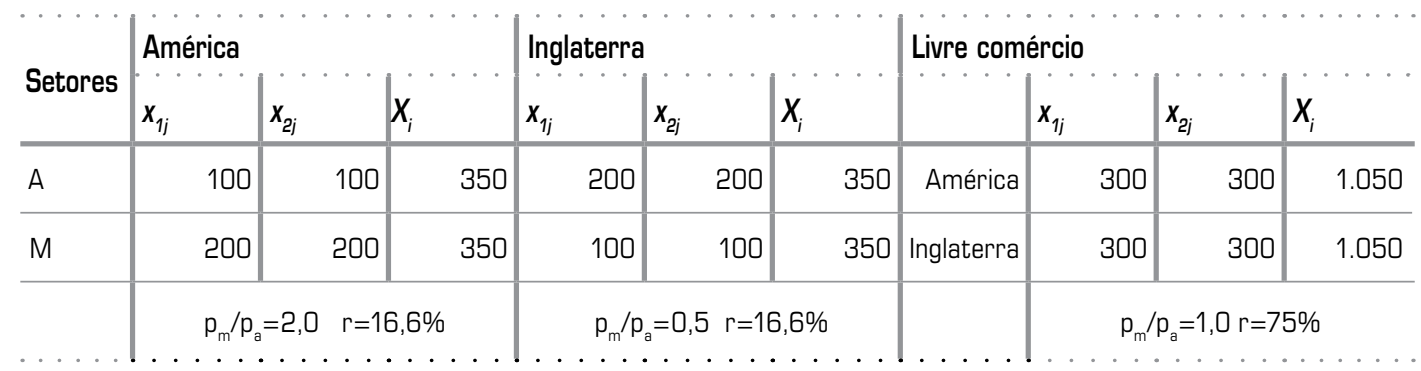

Fonte: EICT (1820, p. 408-411). Obs.: (i) x1j=quarters de trigo, $\mathrm{x} 2 \mathrm{j}=$ =unidades de vestuário; (ii) $\mathrm{A}=$ agricultura; $\mathrm{M}=$ manufaturas.

são do trabalho já se aprofundara o suficiente para a utilização da maquinaria e o barateamento dos bens processados, existindo, contudo, a necessidade de exploração de terras de qualidade inferior. Sendo a produtividade mais elevada na agricultura da América e nas manufaturas da Inglaterra, os dois países resultariam beneficiados, com taxas de lucro acrescidas, caso direcionassem todos os seus recursos para as atividades nas quais usufruíssem de maior vantagem produtiva. É possível acompanhar, na Tabela 3, sem as explicações pertinentes, como Torrens demonstra o salto na taxa de lucro transnacional de $16,6 \%$ para $75 \%$ por conta do estabelecimento do livre comércio entre os dois países (EICT, 1820, p. 406-412).

O que transparece claramente no método desenvolvido na segunda edição do Essay on corn trade, na verdade, é a dependência recíproca entre os setores, num sistema quantitativo de determinação simultânea dos preços relativos e da taxa de lucro, englobando tanto os produtos finais quanto os insumos. ${ }^{16}$ Trata-se, em verdade, de abordagem pioneira para a época, sem que algum segmento da economia apresentasse prioridade analítica sobre os demais. O próprio Torrens, ao discutir a renda fundiária, fornece descrição detalhada da sua maneira de encarar a questão:
Quando as divisões do emprego se instalaram de forma diversificada, a maior parte das necessidades do indivíduo é suprida pelo trabalho alheio; e a maior parte do capital de cada particular é reposta, não pelos artigos que ele mesmo produz, mas por aqueles produzidos por outros capitalistas e que ele obtém por meio da troca e do intercâmbio. $O$ retorno quantitativo que o capitalista aufere, portanto, não depende inteiramente dos poderes produtivos da indústria que ele conduz, mas dos poderes produtivos de todos os ramos da indústria dos quais qualquer um de seus insumos é derivado. Uma diminuição no custo produtivo da matéria-prima eleva os lucros manufatureiros, e uma melhoria na produtividade das manufaturas eleva a taxa de lucro na agricultura (EICT, 1820, p. 420-421).

Fica nítido, portanto, haver Torrens aprimorado, de forma progressiva, um método de análise da economia relativamente robusto e coerente para tratar de forma quantitativa os problemas teóricos de seu tempo, mas cujo potencial, desafortunadamente, não chegou a ser compreendido por seus contemporâneos. 


\section{6_Considerações finais}

No rascunho de Absolute value and exchangeable value (1823), Ricardo indaga como Torrens poderia aplicar o princípio do nivelamento da remuneração para capitais equivalentes sabendo-se que os insumos são diferentes entre as atividades. Noutros termos, como aferir a igualdade entre os capitais senão por meio de seu valor? Ora, prossegue Ricardo, comparando-os com uma terceira mercadoria. Mas, se o valor dos capitais se alterasse, como seria possível aferir em qual dos dois houve a modificação, na ausência de uma medida invariável do valor? "Aqui”, conclui Ricardo, “a regra de Torrens me abandona" (Works IV, 2004, p. 394). Esse questionamento, contudo, desconsiderava o fato de Torrens já haver rejeitado qualquer pretensão de identificar uma medida invariante do valor, como fizera ao refutar pretensão semelhante de Smith, posto que nenhuma mercadoria possuiria custo de produção imune a oscilações. Seria como se, na natureza, observou Torrens em certa oportunidade, tudo mudasse de tamanho ou de massa, tornando impossível definir uma unidade fixa de comprimento ou de peso (EPW, 1821, p. 57, 65).

De outra parte, quando autores modernos como Robbins (1958, p. 51) ou O'Brien (2004, p. 134-135) apontam a falta de originalidade ou mesmo a diversidade na composição material dos capitais como limitação na teoria de Torrens, não parecem levar em conta que ele, a despeito da complexidade do assunto, lograra manejar diversos problemas teóricos fundamentais com relativa eficácia apoiando-se em sua versão compacta da economia a dois setores. A especificidade de o sistema correspondente exigir o recurso ao cálculo simultâneo dos preços e da taxa de lucro para a apuração conjunta do valor dos capitais e do produto refletia tratamento inovador do assunto cujo mérito passou inteiramente despercebido. Para os ricardianos, ao contrário, a rentabilidade geral da economia se estabelecia na margem da exploração agrícola, estendendo-se daí ao restante dos setores por meio da concorrência entre os capitais. É provável, contudo, que a maneira deficiente e tediosa de expor a matéria por Torrens tenha prejudicado a compreensão do que pretendia dizer. Não obstante tal dificuldade, o reconhecimento da interdependência recíproca entre a agricultura e as manufaturas possibilitou-lhe construir uma definição formal da taxa de lucro capaz de enfrentar com desenvoltura os argumentos protecionistas, fornecendo demonstrações quantitativas consistentes das vantagens do livre comércio.

\section{Notas}

${ }^{1}$ Para a biografia do irlandês Torrens (1780-1864), tanto no campo das armas quanto em sua extensa contribuição à economia clássica, veja-se Moore (2004), Fetter (1990, 1962), Robbins (1958, cap. III) e Meenai (1956).

${ }^{2}$ Noutra oportunidade, em reunião do Clube de Economia Política ocorrida em 13 de janeiro de 1831, Torrens apontou o caráter errôneo da concepção ricardiana a respeito do valor, da taxa de lucro e da renda fundiária como razão de seu progressivo abandono pelos economistas (Meenai, 1956, p. 52).

${ }^{3}$ Consulte-se Peach (2009, p. 176 186), Sraffa (Works IV, 2004, p. 305308) e Hollander (1979, p. 208-218).

4 As traduções ao longo do artigo são de nossa autoria.

${ }^{5}$ Logo após a publicação do Essay on corn trade, Ricardo escreve a Malthus: "A teoria de Mr. Torrens, porém, nessa parte da matéria, parece equivocada, pois entendo que o preço das mercadorias será minimamente afetado pelo aumento ou queda no preço do trigo" (17 de abril de 1815, Works VI, 2004, p. 212-213).

${ }^{6}$ De acordo com Ricardo:

"Admitindo-se ampliadas as ocupações da sociedade, que alguns produzam canoas $\mathrm{e}$ equipamentos de pesca, outros sementes e maquinaria primitiva utilizada na agricultura, o mesmo princípio manter-se-ia válido, que o valor de troca das mercadorias estaria fixado pela proporção de trabalho empregue em sua produção; não na sua produção imediata, mas em todos os implementos ou máquinas exigidos para a consecução do trabalho particular no qual foram aplicados" (Works I, 2004, p. 24).

${ }^{7}$ Conforme esclareceu Ricardo:

"Parece então que a acumulação 
de capital, ao gerar diferentes proporções entre os capitais fixo e circulante empregues nas diversas atividades, e ao conferir distintos graus de durabilidade a tais capitais, introduz modificação considerável na regra de aplicação universal nos estágios iniciais da sociedade" (Works I, 2004, p. 66).

${ }^{8}$ Em carta de 26 de outubro de 1818 , James Mill comunica a Ricardo haver recebido nota de Torrens na qual ele dizia estar retornando de Edimburgo, onde se encontrara com McCulloch, quando discutiram de forma amigável a doutrina do valor de Ricardo e combinaram colocar suas divergências no papel, na forma de artigos a serem publicados na imprensa (Works VII, 2004, p. 315-316).

${ }^{9}$ Logo após a publicação dos Principles, Ricardo confidenciou a Trower ter permanecido insatisfeito com a forma como expusera a sua visão sobre o valor que, a si próprio, lhe parecia perfeitamente clara: “[T]enho uma teoria muito sólida em minha mente. Tentei colocar esta teoria no papel a fim de comunicála a outros, mas, devido ao meu escasso conhecimento da arte da composição, não consegui lograr o meu intento" (26 de janeiro de 1818, Works VII, 2004, p. 246).

10 Anteriormente, em A letter to Lord Liverpool (1816), Torrrens já passara a atribuir papel ativo, e não mais reflexo, às condições de cultivo em terras marginais na formação do rendimento dos capitais. "A influência que o preço elevado do trigo, e o cultivo de terras inferiores, têm sobre os lucros do capital, configura-se um dos tópicos mais interessantes e importantes ligados à ciência da riqueza. ${ }^{*}$ Pela lei inexorável da competição, o que reduz o lucro agrícola deve também rebaixar o lucro em todas outras ocupações ( ${ }^{*}$ Veja-se a competente e original publicação Profits on stock, por Dr Ricardo, Esq)" (Torrens, 1816, p. 30). Adiante, no prefácio do Essay on the influence of the corn trade, se encontra a seguinte nota: "O economista experiente capaz de identificar a identidade de princípio na diversidade de expressão verá facilmente em que medida as doutrinas desenvolvidas no original trabalho sobre Economia Política e Tributação foram adotados na presente edição do Ensaio sobre o Comércio de Trigo; e esse reconhecimento geral será suficiente para convencer o leitor menos curioso que, ao omitir as referências ao Sr. Ricardo em cada ocasião particular em que seus princípios possam ter sido adotados, não teve o autor intenção de cometer plágio sob o disfarce de linguagem ou modo de ilustração diferentes" (EICT, 1820, p. xx).

${ }^{11}$ Ao menos cinco dos exemplos constantes no livro contêm erros (EICT, 1820, p. 350, 354, 390, 391 e 399), alguns, possivelmente, por falha de impressão, outros devido a simples confusão com os valores por parte de Torrens ocasionada pela multiplicidade de casos com que lida em sucessão. Em sua obra seguinte, Essay on the production of wealth (EPW, 1821), ele informa haver recebido reclamação de um amigo a respeito do uso pródigo de ilustrações numéricas, ao que respondeu:

"Para dar a esta ciência [economia política] a exatidão e a certeza de que é suscetível, ela deve ser apresentada sob as formas analítica e demonstrativa" (EPW, 1821, p. x).

${ }^{12}$ Confrontado pelo enigma, Ricardo chegou a se equivocar nos exemplos numéricos que elaborou para rebater Malthus (Works VI, 2004, p. 192-194, 212-215; Hollander, 1979, p. 116-190). De qualquer modo, sua resposta qualitativa envolvia, de um lado, a negação liminar do efeito descrito, dado que tal possibilidade violaria o princípio malthusiano da população e, de outro, a aceitação parcial da ideia, mas com a ressalva de que os ganhos extraordinários da agricultura seriam inevitavelmente embolsados pelos proprietários de terras (Works VI, 2004, p. 192-193, 204, 207, 228).

${ }^{13}$ Há um erro de impressão no exemplo, constando $180 \mathrm{em} \mathrm{vez}$ de 100 quarters de trigo como insumo agrícola nas manufaturas (EICT, 1820, p. 399).

${ }^{14}$ Torrens, com efeito, calcula $\mathrm{r}=38 \%$ por utilizar apenas a primeira casa decimal para os preços relativos.

${ }^{15}$ Para os autores favoráveis a uma visão neo-ricardiana de Torrens, consulte-se De Vivo (1996, 1985),
Prendergast (1986) e Langer (1982). A crítica a esse posicionamento é realizada por Hisamatsu (2009), Peach (2001) e Hollander (1995).

${ }^{16}$ Torrens concebia os "preços naturais" obtidos pelo sistema (1) como válidos no longo prazo, podendo os preços efetivos deles se afastar graças às flutuações na oferta e na demanda. Embora se tratasse de um modelo reduzido de equilíbrio geral, esse não seria de tipo estável, pois eventuais desajustes cumulativos nos mercados eram admitidos pelo coronel em sua interessante digressão sobre a Lei de Say, desenvolvida em Essay on the production of wealth (EPW, 1821, p. 42, 50 e cap. VI, seção VI). 
DE VIVO, Giancarlo. Robert Torrens and Ricardo's 'cornratio' theory of profits.

Cambridge Journal of Economics, n. 9, p. 89-92, 1985.

DE VIVO, Giancarlo. Ricardo, Torrens and Sraffa: A summing up. Cambridge Journal of Economics, n. 20, p. 387-391, 1996.

FETTER, Frank W. Robert Torrens: Colonel of Marines and political economist. Economica, n. 29, p. 152-156, May 1962.

FETTER, Frank W. New light on the military career of Robert Torrens. History of Political Economy, v. 22, n. 3 , p. 545-549, 1990.

HANSARD. House of Commons daily debates. Archives.

Disponível em: <www.parliament. uk>. Acesso em: 20 jan. 2012.

HISAMATSU, Taro. Robert Torren's theory of profits reconsidered. History of Economics Review, n. 49, p. 1-14, 2009.

HOLLANDER, Samuel. The economics of David Ricardo. Toronto: University of Toronto Press, 1979.

HOLLANDER, Samuel. Sraffa's rational reconstruction of Ricardo: On three contributions to the Cambridge Journal of Economics. Cambridge Journal of Economics, n. 19, p. 483-489, 1995.
LANGER, G. F. Further evidence for Sraffa's interpretation of Ricardo. Cambridge Journal of Economics, n. 6, p. 397-400, 1982.

MALTHUS, Thomas R. An inquiry into the nature and progress of rent. London: John Murray, 1815.

McCULLOCH, John R.

Mr. Ricardo's theory of exchangeable value vindicated from the objections of R. The

Edinburgh Magazine and

Literary Miscellany, p. 429-431, Nov. 1818.

MEENAI, S. A. Robert Torrens, 1780-1864. Economica, n. 23, p. 4961, 1956.

MOORE, Peter. Robert Torrens (1780-1864). In: MATTHEW, H.G.C. and HARRISON, B. (Eds). Oxford Dictionary of National Biography. Oxford: Oxford University Press, v. 55, p. 56-68, 2004.

O'BRIEN, Dennis P. The classical economists revisited. Princeton: Princeton University Press, 2004. OWEN, Robert. Report to the Committee of the House of Commons on the Poor Laws. In: OWEN, R. The life of Robert Owen. A supplementary appendix to the first volume. London, Effingham Wilson, Appendix I, p. 53-64, 1817.
PEACH, Terry. Hollander, de Vivo and the 'further' evidence for the corn model interpretation of Ricardo: A conspiracy of silence? Cambridge Journal of Economics, n. 25, p. 685-692, 2001.

PEACH, Terry. Interpreting Ricardo. Cambridge: Cambridge University Press, 2009.

PRENDERGAST, R. Malthus's discussion of the corn ratio theory of profits. Cambridge Journal of Economics, n. 10, p. 187-189, 1986.

ROBBINS, Lionel C. Robert Torrens and the evolution of classical economics. London: Macmillan, 1958.

SCHUMPETER, Joseph A. History of economic analysis. London: George Allen \& Unwin, 1963.

SRAFFA, Piero (Ed.) The works and correspondence of David Ricardo. Indianapolis: Liberty Fund, vs. I-IX, 2004.

TORRENS, Robert. An essay on the external corn trade. London: J. Hatchard and Son, $1^{\text {st }}$ ed., 1815.

TORRENS, Robert. A letter to the right honorable the Earl of Liverpool on the state of the agriculture of the United Kingdom. London: J. Hatchard, 1816.
TORRENS, Robert. Strictures on Mr. Ricardo's doctrine respecting exchangeable value [1818]. In: GROENEWEGEN, Peter D. (Ed.). The economists refuted and other early economic writings. Robert Torrens. Fairfield: Augustus M. Kelley, p. 77-82, 1993. TORRENS, Robert. Mr. Owen's plan for relieving the national distress [1819]. In: GROENEWEGEN, Peter D. (Ed.). The economists refuted and other early economic writings. Robert Torrens. Fairfield: Augustus M. Kelley, p. 83-103, 1993.

TORRENS, Robert. An essay on the influence of the external corn trade. London: J. Hatchard and Son, $2^{\text {nd }}$ ed., 1820.

TORRENS, Robert. An essay on the production of wealth. London: Longman, Hurst, Rees, Orme and Brown, 1821.

TORRENS, Robert. An essay on the external corn trade. London: Longman, Rees, Orme, Brown and Green, $3^{\text {rd }}$ ed., 1826.

O autor agradece o apoio do CNPq.

E-mail de contato do autor:

rogerio.arthmar@ufes.br

Artigo recebido em abril de $2013 \mathrm{e}$ aprovado em julho de 2013. 